\title{
Essential oil of Pterodon polygalaeflorus Benth attenuates nociception in mice
}

\author{
A.N. Coelho-de-Souza ${ }^{1}$, C.F. dos-Santos ${ }^{1}$, L.N. Lopes-Filho ${ }^{2}$, F.R. Holanda ${ }^{1}$, A.C. Oliveira ${ }^{1}$, \\ Y.A. Gomes-Vasconcelos ${ }^{1}$, K.A. Oliveira ${ }^{1}$, F.W. Ferreira-da-Silva ${ }^{3}$, K.S. Silva-Alves ${ }^{1}$ and \\ J.H. Leal-Cardoso ${ }^{1}$ \\ ${ }^{1}$ Laboratório de Fisiologia Experimental, Instituto Superior de Ciências Biomédicas, Universidade Estadual do Ceará, \\ Campus do Itaperi, Fortaleza, CE, Brasil \\ ${ }^{2}$ Centro Universitário Christus, Fortaleza, CE, Brasil \\ ${ }^{3}$ Curso de Engenharia Civil, Centro de Ciências Exatas e Tecnologia, Universidade Estadual Vale do Acaraú, \\ Campus CIDAO, Sobral, CE, Brasil
}

\begin{abstract}
Essential oils (EO) are volatile liquids responsible for the aroma of plants. Pterodon polygalaeflorus seeds have received widespread use in folk medicine for the treatment of inflammatory diseases. For this reason and because Pterodon polygalaeflorus seeds have great EO content, which is frequently pharmacologically active, the present study aimed to evaluate the antinociceptive effect of EO from Pterodon polygalaeflorus (EOPPgfl) and its acute toxic effects. The EEOPPgfl sample, which was extracted by steam distillation of the seeds, had a yield of $2.4 \%$ of the seeds weight and had, as major constituents, beta-elemene (48.19\%), trans-caryophyllene (19.51\%), and epi-bicyclosesquiphellandrene (12.24\%). The EOPPgfl sample showed mild acute toxicity and its calculated median lethal dose $\left(\mathrm{LD}_{50}\right)$ was $3.38 \mathrm{~g} / \mathrm{kg}$. EOPPgfl $(20-60 \mathrm{mg} / \mathrm{kg}) \mathrm{showed}$ antinociceptive activity as evidenced by several tests and inhibited writhing induced by acetic acid. The maximum effect was obtained with the $30 \mathrm{mg} / \mathrm{kg}$ dose and at $60 \mathrm{~min}$ after its administration. EOPPgfl also decreased formalin-induced nociception, as verified by the inhibition of the first and second phase of the formalin test. At $30 \mathrm{mg} / \mathrm{kg}$, EOPPgfl also decreased thermally stimulated nociception. Nociception may be related to inflammatory and antiedematogenic activity and at doses ranging 10-100 mg/kg, EOPPgfl blocked dextran- and carrageenan-induced edema. The results demonstrated that EOPPgfl presented, at doses approximately 100 times smaller than $L_{50}$, an antinociceptive effect that probably was due to anti-inflammatory activities.
\end{abstract}

Key words: Essential oil; Pterodon polygalaeflorus; Antinociception; Anti-inflammatory activities; Beta-elemene; Caryophyllene

\section{Introduction}

Aromatic formulations have been used throughout human history for spiritual, social, and medicinal purposes. For medicinal purposes, they are not usually used as essential oils but mainly as infusions, teas, and incense (1).

Essential oils (EO) are volatile and oleaginous liquids with usually pleasant aromas that provide odor to plants (2). EO of aromatic plants from Northeast Brazil have been studied from the chemical $(3,4)$ and pharmacologic point of view $(1,3,5,6)$ showing great potential for therapeutic use. Northeastern flora is abundant in aromatic species, whose EO consist of a mix of compounds, mostly phenylpropanoic and terpene derivatives. This chemical complexity allows EO to have several biological effects, such as antiparasitic (7), antimicrobial (8), analgesic and anti-inflammatory (9), diuretic and hypotensive (10), antimalarial (11), gastro-protector $(1,6)$, cell excitability inhibitor (12-14), among others.
Pterodon polygalaeflorus Benth or Commilobium polygalaeflorus, popularly known as "sucupira branca" (white sucupira), is a tree common in the Brazilian Northeast region and abundant in Maranhão and Piauí states $(15,16)$. It has great regional importance because of the widespread use of its shell and seeds in popular medicine as hydroalcoholic infusions for the treatment of chronic diarrhea (16), pharyngitis (15), and chronic pain and inflammation, such as in arthritis (17) and rheumatic diseases.

The chemical composition and pharmacological effects of the essential oil of Pterodon polygalaeflorus Benth (EOPPgfl) seeds have been previously investigated $(15,16)$. It has demonstrated antispasmodic action on tracheal smooth muscle by blockade of voltage-operated calcium channels (15) and on intestinal smooth muscle by myogenic mechanisms, mainly mediated through an intracellular mechanism (16).

Correspondence: J.H.L. Cardoso: <lealcard@gmail.com> 
Due to its popularity in the treatment of inflammatory diseases, its previously observed pharmacological activity, and the great EO yield of the seeds, the present study aimed to evaluate the antinociceptive effect of a new sample of EOPPgfl in experimental models of pain and the acute toxic effects in order to seek new substances with therapeutic potential.

\section{Material and Methods}

\section{Extraction and chemical analysis of EOPPgfl}

EOPPgfl was extracted from the seed of $P$. polygalaeflorus Benth collected in the municipality of São Raimundo das Mangabeiras, Maranhão state in February 1999 by steam distillation method. Chemical composition was determined by gas chromatography coupled to mass spectrometry in the Technological Development Park of Federal University of Ceará (PADETEC-UFC) by Craveiro (18), as previously described. Briefly the conditions were as follows: Hewlett-Packard 6971 (USA); dimethylpolysiloxane DB-1 fused silica capillary column $(30 \mathrm{~m} \times 0.25 \mathrm{~mm} ; 0.1 \mu \mathrm{m})$; helium (1 $\mathrm{mL} / \mathrm{min})$ as carrier gas; injector temperature: $250^{\circ} \mathrm{C}$; detector temperature: $200^{\circ} \mathrm{C}$; column temperature: $35-180^{\circ} \mathrm{C}$ at $4^{\circ} \mathrm{C} / \mathrm{min}$ and then $180-250^{\circ} \mathrm{C}$ at $10^{\circ} \mathrm{C} / \mathrm{min}$; and mass spectra: electronic impact $70 \mathrm{eV}$. The compounds were identified using a NIST mass spectral library search (more information on https://chemdata.nist.gov/).

\section{Drugs}

All drugs were of analytical purity. Dextran, carrageenan, histamine, and serotonin were from Sigma Chemical Company (USA). Cyproheptadine, formaldehyde, acetic acid, indomethacin, morphine, and naloxone were from Cinética Química Ltda. (Brazil).

Solutions were prepared by adding the pure substance to sterile saline $(0.9 \% \mathrm{NaCl} w / \mathrm{v})$. EOPPgfl was prepared in sterile saline, containing Tween $80,0.1 \% \mathrm{v} / \mathrm{v}$, followed by automatic stirring. After homogenization, the solution was administered by the orogastric route.

\section{Animals}

This study complied with the ethical principles for animal research. Swiss mice $(25-30 \mathrm{~g})$ from the Central Vivarium of Federal University of Ceará were kept under constant temperature $\left(22 \pm 2^{\circ} \mathrm{C}\right)$ with a $12 \mathrm{~h}$ light $/ 12 \mathrm{~h}$ dark cycle and free access to food and water in the Laboratory of Electrophysiology of Excitable Tissue 1-3 days prior to the experiment. The study was done from 2000 to 2002.

\section{Assessment of acute toxic effects}

The evaluation of acute toxic effects was done by determination of the median lethal dose $\left(L D_{50}\right)$ and observation of changes in behavioral parameters.

To determine $L D_{50}$, the animals were randomly separated into 6 groups: 1 control and 5 experimental groups. Each experimental group received, through orogastric cannula, different concentrations of EOPPgfl $(1-8 \mathrm{~g} / \mathrm{kg})$. The control group received only vehicle $(0.1 \%$ Tween 80 in $0.9 \%$ saline). The animals were then placed in cages with water and feed ad libitum and observed for a period of $72 \mathrm{~h}$. After this period, the number of deaths in each group was observed and reported as percentage of the total number of animals. Calculation of $L_{50}$ was done by semilogarithmic interpolation, where the EOPPgfl doses were plotted on the abscissa axis and the values corresponding to the probit percentage of deaths on the ordinate axis.

To evaluate changes in behavioral parameters, animals were randomly separated in 5 experimental groups (10 animals/group). The animals were initially observed for $72 \mathrm{~h}$ for the following behavioral parameters: alertness, analgesia, spontaneous motor activity, locomotion, sedation, response to touch, nasal secretion, piloerection, ptosis, dyspnea, urination, diarrhea, and seizure. They were then treated with the same doses of EOPPgfl or vehicle and observed for the same parameters during the first $3 \mathrm{~h}$ and, at 24-h intervals, for $72 \mathrm{~h}$.

\section{Antinociceptive activity}

To evaluate the EOPPgfl anti-nociceptive activity, the acetic acid-induced writhing test (19), the paw-licking response to the formalin test (20), and the hot plate test (21) were used.

For the writhing test, different groups of animals $(n=$ 8-10 animals/group) received EOPPgfl (10-100 mg/kg, orally) or vehicle $(0.1 \%$ Tween 80 in sterile saline, orally), $60 \mathrm{~min}$ before, or indomethacin $(10 \mathrm{mg} / \mathrm{kg}$, ip), $30 \mathrm{~min}$ before noxious stimulation with ip injection of acetic acid $(0.6 \% \mathrm{v} / \mathrm{v} ; 0.1 \mathrm{~mL} / 10 \mathrm{~g}$ body weight). Then, abdominal writhes were recorded for $20 \mathrm{~min}$, starting $10 \mathrm{~min}$ after acetic acid injection. In another experimental series, a time course for the effect of the oil (30 mg/kg, orally) administered $15,30,60$, and $120 \mathrm{~min}$ before noxious stimulation was carried out. Antinociceptive activity is reported as the number of abdominal constrictions.

For the formalin test, different groups of animals received EOPPgfl $(10-100 \mathrm{mg} / \mathrm{kg}$ ) orally or vehicle, $60 \mathrm{~min}$ before the treatment with $20 \mu \mathrm{L}$ of formalin $(2.5 \% \mathrm{v} / \mathrm{v})$ administered into the sub-plantar region of the right hind paw. The time the animal spent licking the paw during the first 5 min (early phase) and from 15 to 30 min (late phase) post-formalin injection served as measures of sensitivity. The test was done at ambient temperature of $22-26^{\circ} \mathrm{C}$ and care was taken to exclude environmental disturbance (high temperature, noise, and excessive movement) that might interfere with the animal's response. In another experimental series, a group of animals received naloxone $(2 \mathrm{mg} / \mathrm{kg}, \mathrm{sc}$ ), an opioid antagonist, $15 \mathrm{~min}$ before treatment with oil ( $60 \mathrm{mg} / \mathrm{kg}$ orally) or morphine $(5 \mathrm{mg} / \mathrm{kg}, \mathrm{sc})$. After 30 min of morphine administration, the formalin test was performed.

For the hot plate test, a mouse was placed on a plate maintained at $50.0 \pm 1^{\circ} \mathrm{C}$ and the latency of its reaction to 
this nociceptive stimulus (number of seconds before it licked its hind paw or jumped) was quantified, with an interruption time $\leqslant 45 \mathrm{~s}$. The test used only mice that in a pretest showed a hot plate reaction time $\leqslant 20 \mathrm{~s}$. The latency of the reaction to nociception was measured at time 0 (60 $\mathrm{min}$ after EOPPgfl, $30 \mathrm{mg} / \mathrm{kg}$, or vehicle administration) and then at 30 min intervals up to the 180th min.

\section{Antiedematogenic activity}

Antiedematogenic activity of EOPPgfl was evaluated by the carrageenan-, dextran-, or formalin-induced paw edema test.

In order to obtain carrageenan- and dextran-induced paw edema, the phlogistic agents (both $300 \mu \mathrm{g} / \mathrm{paw}$ ) were injected into the sub-plantar region of the right hind paw. The contralateral paw received an equal volume of sterile saline. The animals received EOPPgfl $(10-60 \mathrm{mg} / \mathrm{kg}$ ) orally or vehicle. Indomethacin $(10 \mathrm{mg} / \mathrm{kg}$, ip) or cyproheptadine $(10 \mathrm{mg} / \mathrm{kg}$, ip) were used as positive controls. The time course of the carrageenan-induced paw edema was considered to have three phases: a first (from 1 to $90 \mathrm{~min}$ ), a second (from 91 to $150 \mathrm{~min}$ ), and a third phase (from 151 to $240 \mathrm{~min}$ ) (22). For formalin-induced paw edema, the same animals submitted to the nociception test were used. In these animals, formalin $(20 \mu \mathrm{L}$ of $2.5 \%$ formalin) was injected $s c$ into the right hind paw. The animals received EOPPgfl $(60 \mathrm{mg} / \mathrm{kg})$ orally or vehicle. Paw licking was then measured during the first 5 min (considered as the first phase of formalin test) and at $15 \mathrm{~min}$ after the formalin injection (considered as the second phase of the test).

Paw edema volumes for antiedematogenic activity tests were measured with a plethysmometer (Panlab, S.L. U., Digital Water Plethysmometer Le 7500, Spain). Edema was considered to be the difference in volume between two paws, among the different time-periods and time zero.

\section{Statistical analysis}

All data are reported as means $\pm S E$, where $n$ is the number of experiments. The difference between two groups was assessed by the unpaired Student's $t$-test. The significance $(P<0.05)$ of the results that demanded multiple comparisons was initiated with the Kolmogorov-Smirnov test for normality of data distribution. In the cases in which normality was rejected, Kruskal-Wallis one-way ANOVA on ranks followed by Dunn's post hoc test was done; otherwise parametric one-way ANOVA followed by Bonferroni or Holm-Sidak post hoc test was employed. For each experimental series analyzed and parametric data, the ANOVA parameters d.f. ${ }_{1}$ (degree of freedom related to the number of independent variables, between groups), d.f.2 (degree of freedom related to the number of observations in each group, within group), and $F$ (ratio of the mean square variation estimates of data between groups and within group) were used. For non-parametric data, ANOVA on rank parameters d.f. (degree of freedom) and $\mathrm{H}$ (value computed by ranking all observations from smallest to largest without regard to treatment group) was used. $\mathrm{P}<0.05$ was considered significant for all post hoc tests. Statistical analysis was done using Sigma Stat and Sigma Plot software (Systat Inc., USA).

\section{Results}

\section{Extraction and chemical analysis of EOPPgfl}

The oil extracted by steam distillation of seeds gave a yield of $2.4 \%$ weight. In the oil sample, seven sesquiterpenes (with \% of oil weight) were identified: beta-elemene $(48.19 \%)$, trans-caryophyllene $(19.51 \%)$, epi-bicyclosesquiphellandrene $(12.24 \%)$, gamma-elemene $(4.44 \%)$, alpha-copaene $(4.13 \%)$, alpha-humulene (3.32\%), alloaromadendrene (2.45\%); and two alcohols: $(3.17 \%)$ spatulenol and $(2.55 \%)$ farnesol.

\section{Toxic effect of EOPPgfl}

As can be seen in Table 1, no death occurred in animals treated with doses of EOPPgfl below or equal to $3 \mathrm{~g} / \mathrm{kg}$. However, at doses above $3 \mathrm{~g} / \mathrm{kg}$, toxic signs such as lethargy, motor incoordination, tachypnea, ptosis, and asphyxia were observed and the calculated $\mathrm{LD}_{50}$ was $3.38 \mathrm{~g} / \mathrm{kg}$.

\section{Antinociceptive activity}

EOPPgfl $(20,30$, and $60 \mathrm{mg} / \mathrm{kg})$ and indomethacin (10 mg/kg) significantly reduced $(P<0.05$, ANOVA, Dunn test) writhing number from $51.9 \pm 1.62$ counts $(n=10)$ (control value)

Table 1. Symptoms and deaths of animals treated with essential oil of Pterodon polygalaeflorus (EOPPgfl).

\begin{tabular}{lccc}
\hline Group & Dose $(\mathrm{mg} / \mathrm{kg})$ & Deaths & Symptoms \\
\hline Control & - & 0 & none \\
EOPPgfl & 1000 & 0 & none \\
& 2000 & 0 & none \\
& 3000 & 0 & Lethargy, motor incoordination and anesthesia \\
& 4000 & $\mathrm{n}=5(62.5 \%)$ & Lethargy, motor incoordination and anesthesia \\
& 8000 & $\mathrm{n}=5(62.5 \%)$ & Motordination, tachypnea and asphyxia
\end{tabular}

$\mathrm{n}=8$ animals for control and each dose. 
A

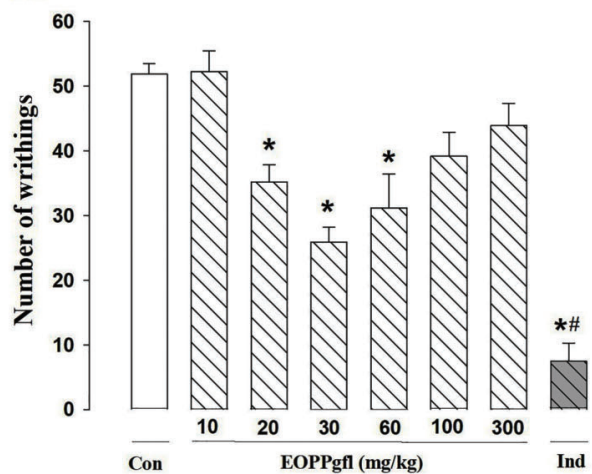

B

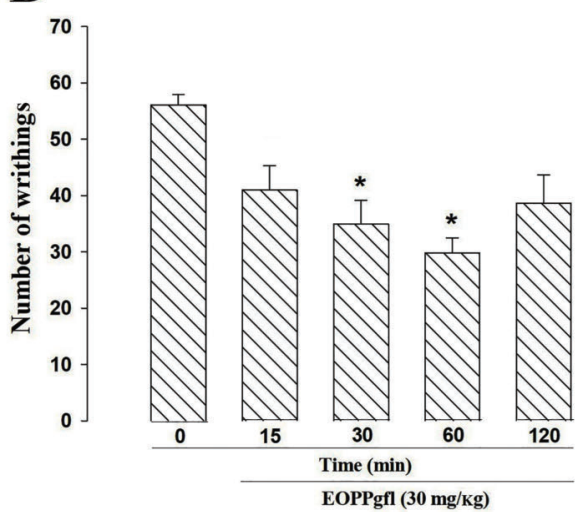

Figure 1. Effect of essential oil of Pterodon polygalaeflorus (EOPPgfl) on acetic acid-induced writhing. $A$, Effect of several doses $(10-300 \mathrm{mg} / \mathrm{kg}$, orally) of EOPPgfl and of indomethacin (Ind, $10 \mathrm{mg} / \mathrm{kg}$, ip) on the number of writhings; EOPPgfl and Ind were administered 60 and $30 \mathrm{~min}$, respectively, before acetic acid administration. Ten min after acetic acid administration, the writhings were counted during $20 \mathrm{~min}$. Con: control. $B$, Time course of the EOPPgfl effect $(30 \mathrm{mg} / \mathrm{kg}$, orally). Each animal received a single dose of EOPPgfl. Data are reported as means $\pm S E(n=8-10)$. $A$, ${ }^{*} \mathrm{P}<0.001$ compared to control; ${ }^{*} \mathrm{P}<0.001$ compared to $30 \mathrm{mg} / \mathrm{kg}$ EOPPgfl (one-way ANOVA, d.f. $1=7$, d.f. . $_{2}=60, F=17.931$, followed by Holm-Sidak post hoc test). $B,{ }^{*} \mathrm{P}=0.002$ compared to control (Kruskal-Wallis ANOVA on ranks, d.f. $=4, \mathrm{H}=16.923$, followed by Dunn's post hoc test).

to $35.2 \pm 2.64(n=10), 25.9 \pm 2.32(n=10), 31.2 \pm 5.8$, and $7.5 \pm 2.8$ counts $(n=8)$, respectively (Figure $1 \mathrm{~A})$. This reduction corresponded to $32.2,50.1,39.8$, and $85.5 \%$. The effect of EOPPgfl was time-dependent since EOPPgfl (30 mg/kg), administered $15,30,60$, or 120 min prior to the time of writhing measurement, induced writhing reduction that amounted to $27.0,37.7,46.8$, and $31.2 \%$, respectively. The EOPPglf-induced writhing reduction is shown in Figure 1B; the reduction was significant at 30 and $60 \mathrm{~min}$.

In the formalin test, EOPPgfl $(20,30$, and $60 \mathrm{mg} / \mathrm{kg})$ significantly reduced the time the animal spent licking its paw in both phases of the test (Figure $2 A$ and $B$ ) compared to the control (1st phase $74.85 \pm 2.26 s(n=8)$ and

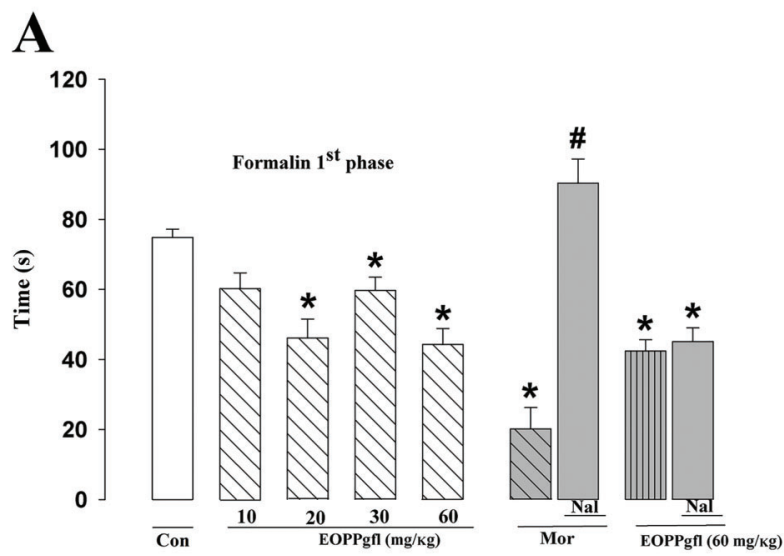

B

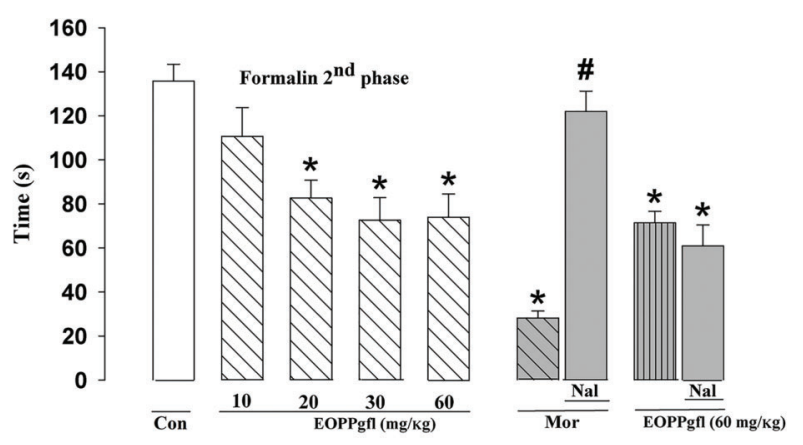

Figure 2. Effect of essential oil of Pterodon polygalaeflorus (EOPPgfl) on formalin test. Effect of several doses $(10-60 \mathrm{mg} / \mathrm{kg}$, orally) of EOPPgfl, morphine (Mor; $5 \mathrm{mg} / \mathrm{kg}, s c$ ), and naloxone ( $\mathrm{Nal} ; 2 \mathrm{mg} / \mathrm{kg}, \mathrm{sc}$ ) on paw licking from 0 to $5 \mathrm{~min}$ (1st phase of formalin test; panel $A$ ) and from 15 to $30 \mathrm{~min}$ (2nd phase of formalin test; panel $B$ ) after formalin administration (intraplantar injection of $20 \mu \mathrm{L}$ of $2.5 \%$ formalin (v/v) solution in distilled water). Con, control (intra-paw injection of $20 \mu \mathrm{L}$ of saline). Data are reported as means $\pm \mathrm{SE}(\mathrm{n}=8)$. $A,{ }^{*} \mathrm{P}<0.001$ compared to control; ${ }^{\#} \mathrm{P}<0.001$ compared to Mor (Kruskal-Wallis ANOVA on ranks, d.f. $=8, \mathrm{H}=43.151$ followed Dunn's post hoc test). $B,{ }^{*} \mathrm{P}<0.001$ compared to control; ${ }^{\#} \mathrm{P}<0.001$ compared to Mor (parametric one-way ANOVA, d.f. ${ }_{1}=8$, d. . $_{2}=55, \mathrm{~F}=11.961$ followed Bonferroni post hoc test).

the $2 \mathrm{nd}$ phase $135 \pm 7.61 \mathrm{~s}(\mathrm{n}=8))$. At the dose of $20 \mathrm{mg} / \mathrm{kg}$, for the first (Figure 2A) and second phase (Figure 2B), the time of licking was reduced to 46.1 and $82.6 \mathrm{~s}$, respectively, at the dose of $30 \mathrm{mg} / \mathrm{kg}$, to 59.7 and $72.6 \mathrm{~s}(\mathrm{n}=7)$, and at the dose of $60 \mathrm{mg} / \mathrm{kg}$, to 44.3 and $74.1 \mathrm{~s}(\mathrm{n}=7)$. This effect was not altered ( $P>0.05$, ANOVA) by subcutaneous injection of naloxone, an antagonist of opioid receptor (Figure $2 \mathrm{~A}$ and $\mathrm{B}$ ).

As assessed by the hot plate test, EOPPgfl significantly increased the latency time for nociceptive response to the thermal stimulus starting at $30 \mathrm{~min}$ and spanning throughout the observation period of $180 \mathrm{~min}$. The peak of EOPPgfl effect occurred at $60 \mathrm{~min}$ when the latency time 
increased from 6.5 (control value) to $15.0 \mathrm{~s}$. The effect of EOPPgfl was similar to that of morphine, although the effect of the oil lasted longer (Figure 3).

\section{Antiedematogenic activity}

EOPPgfl significantly inhibited the carrageenaninduced edema from the 30th to the 240th min of the experiment (Figure $4 \mathrm{~A} 1$ and $\mathrm{A} 2$ ). At the three phases of carrageenan-induced edema, the paw volume increase underwent inhibition with all EOPPgfl doses, as demonstrated by the decrease of the area under the curve of Figure 4A2. At doses of $100 \mathrm{mg} / \mathrm{kg}$, the effect of EOPPgfl was similar to the effect of indomethacin (inhibition of $80 \%$ ). EOPPgfl at 30 and $60 \mathrm{mg} / \mathrm{kg}$ also inhibited the edema induced by dextran (Figure 4B) and at $60 \mathrm{mg} / \mathrm{kg}$ inhibited formalin-induced edema (2.5\%) (Figure 4C). In the edema induced by dextran, the effect of EOPPgfl (30 and $60 \mathrm{mg} / \mathrm{kg}$ ) occurred throughout the observation period and was similar to the effect of cyproheptadine. EOPPgfl at $60 \mathrm{mg} / \mathrm{kg}$ produced a $55.7 \%$ inhibition of the edema caused by formalin.

\section{Discussion}

This study was designed to evaluate the antinociceptive, antiedematogenic, and acute toxic effects of EOPPgfl in experimental models of pain and inflammation. The results demonstrated that EOPPgfl, with the chemical composition here described, presented very low acute toxicity and antinociceptive effects, probably due to antiinflammatory activities.

The sample of $P$. polygalaefllorus seeds of the present investigation produced the same yield $(2.4 \%$ of EO) found by Evangelista et al. (15) and Leonhardt et al (16), thus confirming the great EO yield of the seeds. It is also worth mentioning that this yield was obtained using a cheap and easy method of EO extraction: steam distillation (23). The chromatographic analysis identified $100 \%$ of the compounds, predominantly sesquiterpenes, which largely differed from that of the previous investigation $(15,16)$. In the present case, there was a major constituent (betaelemene, $48.2 \%$, followed by trans-caryophyllene, $19.5 \%$ ), whilst in the previous study a major constituent was not identified ( $\beta$-cariophyllene, $20.6 \%$, followed by spatulenol, $16.6 \%)$. This is not surprising, since it is known that EO compositions differ with the place and season of collection (2); the time of collection of the present and previous samples differed (February vs October, respectively). Since there is a large difference in chemical composition and it may affect the pharmacological results, care should be taken to obtain the appropriate EOPPgfl sample.

The results demonstrated that the calculated $L D_{50}$ for EOPPgfl, given orally, was $3.4 \mathrm{~g} / \mathrm{kg}$ allowing the oil to be classified within the category of low-toxicity essential oils (2) and to be considered a safe oil regarding acute toxic aspects. It is important to note that the doses that inhibit nociception and edema formation in the various models tested are in the range of $10-100 \mathrm{mg} / \mathrm{kg}$, which represent doses below $3 \%$ of $L_{50}$. Thus, EOPPgfl can be considered to have high therapeutic potentiality. Moreover, this study also showed that EOPPgfl possesses antinociceptive activity on chemical and thermal nociception models.

In the hot plate test, $30 \mathrm{mg} / \mathrm{kg}$ EOPPgfl increased the latency time to the thermal stimulus. This test of thermal nociception is a good method for measuring the effects of opioid analgesics but it is not sensitive to the analgesic effects of nonsteroidal anti-inflammatory agents $(24,25)$. EOPPgfl increased the response time to the thermal stimulus in the hot plate test, suggesting that EOPPgfl acted primarily at the spinal medulla and/or higher central nervous system levels (20), but not excluding an indirect
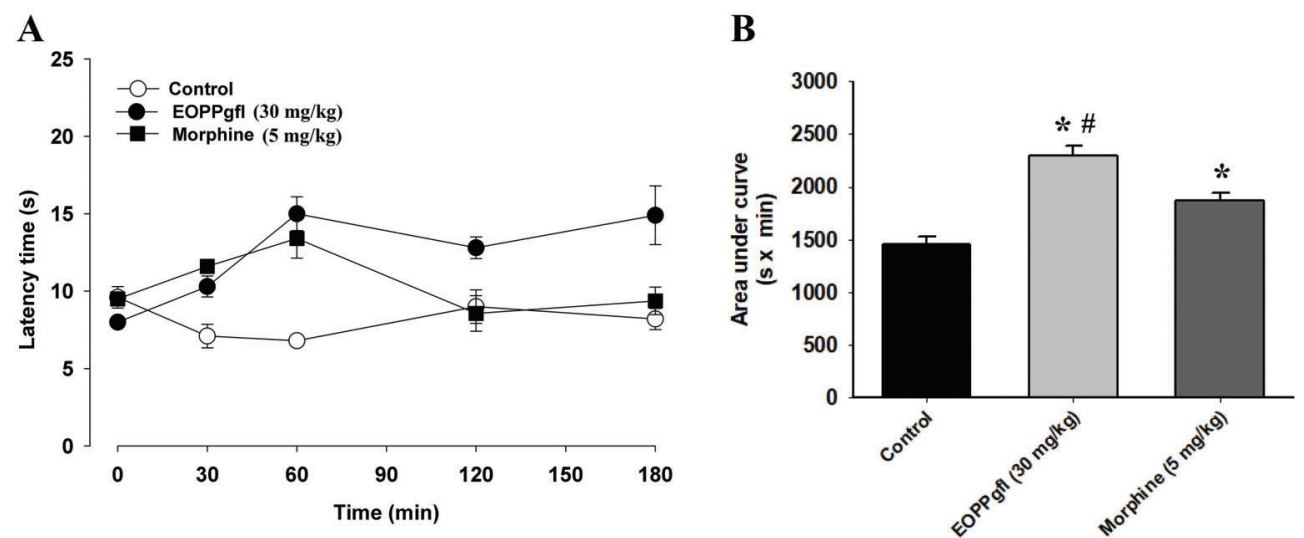

Figure 3. Effect of essential oil of Pterodon polygalaeflorus (EOPPgfl) on noxious thermal stimulation. $A$, Time course of latency of nociceptive response to paw exposure to $50 \pm 0.5^{\circ} \mathrm{C}$. Data are reported as means $\pm S E(n=8)$. $B$, Area under the curves shown in $A$. ${ }^{*} \mathrm{P}<0.05$ compared to control; ${ }^{\#} \mathrm{P}<0.001$ compared to morphine (parametric one-way ANOVA, d.f. ${ }_{1}=2$, d.f. ${ }_{2}=21, \mathrm{~F}=27.191$, followed Holm-Sidak post hoc test). 

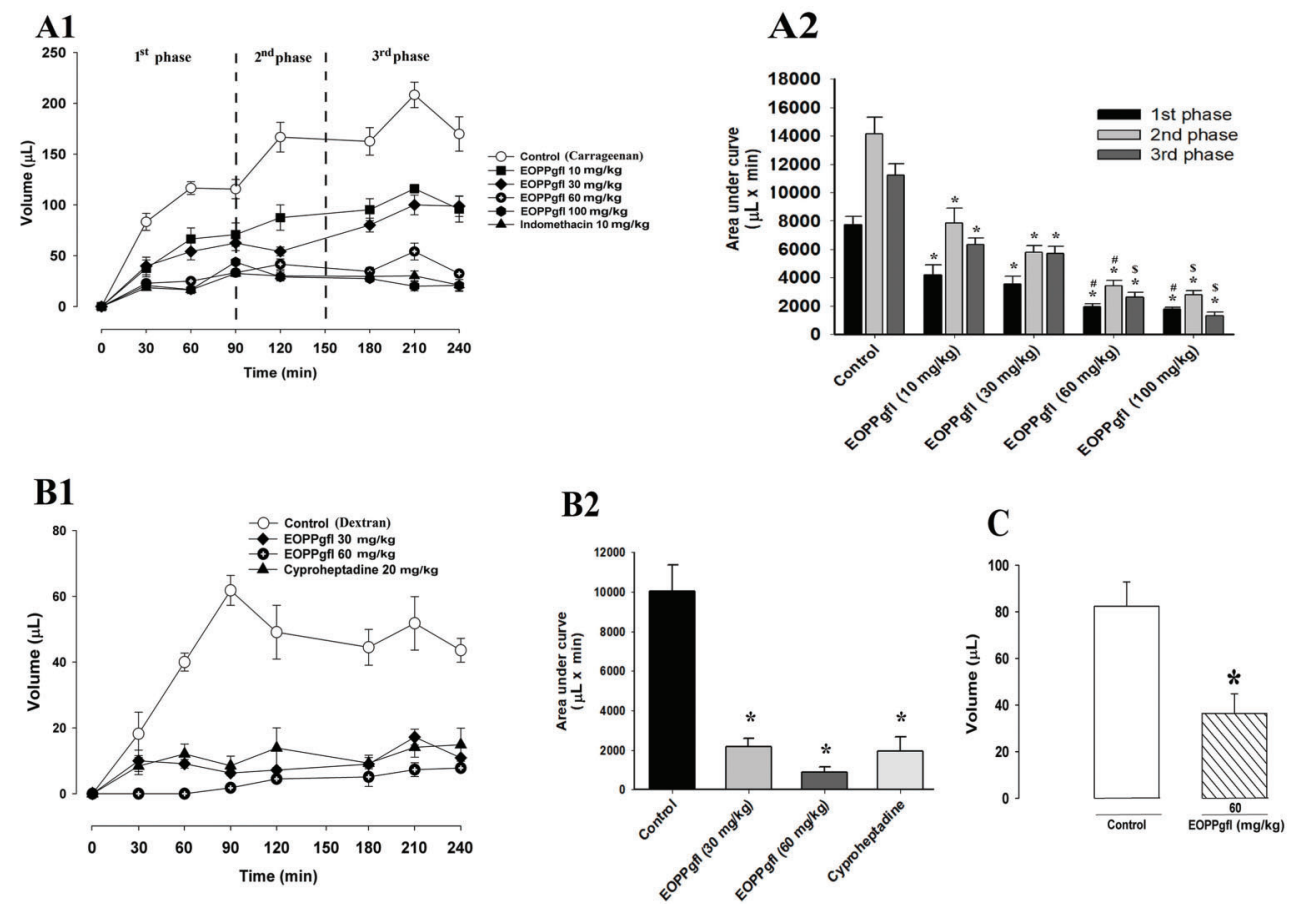

Figure 4. Effect of essential oil of Pterodon polygalaeflorus (EOPPgfl) on carrageenan-, dextran-, and formalin-induced edema. A1, Time course of alteration induced by EOPPgfl (orally) and indomethacin (10 mg/kg, ip) on edema induced by carrageenan (control, intraplantar injection of $50 \mu \mathrm{L}$ of $6.0 \mathrm{mg} / \mathrm{mL}$ carrageenan solution in saline). A2, Area under the curves shown in $A 1 \mathrm{for}$ the $1 \mathrm{st}$, 2nd, and 3rd phase of carrageenan edematogenic effect. ${ }^{*} \mathrm{P}<0.001$ compared to control; ${ }^{\#} \mathrm{P}<0.001 \mathrm{compared}$ to $10 \mathrm{mg} / \mathrm{kg} ;{ }^{\$} \mathrm{P}<0.001 \mathrm{compared}$ to 10 and $30 \mathrm{mg} / \mathrm{kg}$ (parametric one-way ANOVA, 1st phase, d.f. $._{1}=4$, d.f. $._{2}=35, F=23.675 ;$ 2nd phase, d.f. $=4$, d.f. $=35$, $F=35.545 ; 3$ rd phase, d.f. $1=4$, d.f. $=35, F=59.183$, followed by Holm-Sidak post hoc test). B1, Time course of alteration induced by EOPPgfl (orally) and cyproheptadine $(10 \mathrm{mg} / \mathrm{kg}$, ip) on edema induced by dextran (control, intraplantar injection of $50 \mu \mathrm{L}$ of $6.0 \mathrm{mg} / \mathrm{mL}$ dextran solution in saline). B2, Area under the curves shown in $B 1$ for dextran edematogenic effect. ${ }^{*} \mathrm{P}<0.05$ compared to control (parametric one-way ANOVA, d.f. ${ }_{1}=3$, d.f. ${ }_{2}=28, F=28.003$, followed by Holm-Sidak post hoc test). $C$, Alteration induced by EOPPgfl (orally) on edema induced by formalin (control, intraplantar injection of $20 \mu \mathrm{L}$ of formalin $2.5 \% \mathrm{v} / \mathrm{v}$ in saline). ${ }^{*} \mathrm{P}=0.003$, compared to control (non-paired $t$-test). Data are reported as means \pm SE $(n=8-10$ in all cases)

mechanism. In order to investigate the participation of an indirect mechanism of the effect of EOPPgfl, its action in acetic acid-induced writhing and in the formalin tests was investigated and the oil showed antinociceptive effects in both tests.

Acetic acid-induced writing is a model sensitive to analgesic substances of central or peripheral action, allowing the assessment of varied mechanisms of action (19). Acetic acid causes the release of endogenous mediators such as PGE2 and PGF2 $\alpha$, histamine, bradykinin, and serotonin and stimulates the nerve endings directly by $\mathrm{pH}$ reduction (1). Therefore, the effectiveness of EOPPgfl in decreasing acetic acid-induced contortions, although suggesting an involvement of primarily neural mechanisms, does not exclude a antinociceptive effect of EOPPgfl due to anti-inflammatory activity, secondary to inhibitory action on the phlogistic activity of autacoids such as histamine, serotonin, and/or prostaglandin. Despite a dose-dependent relationship, EOPPgfl doses above $60 \mathrm{mg} / \mathrm{kg}$ no longer had a significant antinociceptive effect in acetic acid-induced writhing, which was surprising. Although we do not have a clear explanation for this finding, it can be suggested that in these doses, some components of EOPPgfl somehow prevent the action of the constituent promoting antinociceptive activity. Although pronounced, the effect of EOPPgfl was lower than that caused by indomethacin $(10 \mathrm{mg} / \mathrm{kg}$, ip), a peripherally acting drug that inhibits prostaglandin synthesis

It is known that the formalin test is a behavioral evaluation method used to measure the efficacy of antinociceptive agents with different mechanisms of action $(25,26)$. In the first phase, starting immediately after formalin injection and with a duration of 3 to $5 \mathrm{~min}$ $(20,27)$, the nociception is attributed to a peripheral neural mechanism and related to the direct chemical stimulation of type $C$ nociceptor afferent fibers and, in part, of type $A \delta$ fibers and is associated with the release of excitatory amino acids, nitric oxide, and substance $P$. In the second phase, which begins 15 to 20 min after the injection and lasts for 20 to $40 \mathrm{~min}$, pain is attributed to inflammatory activity 
and/or alteration of central processing $(25,28,29)$. In the formalin test, EOPPgfl was effective in both first and second phases of the test. The effectiveness of EOPPgfl during the first phase of formalin test suggests a peripheral neural mechanism. On the other hand, the effectiveness EOPPgfl during the second phase of formalin test is consistent with an anti-inflammatory action and/or alteration of central processing. In these effects, there was probably no involvement of opioid receptors since they were not blocked by naloxone (30), which blocked the effect of morphine.

Velozo et al. (31) showed that $P$. polygalaeflorus has anti-inflammatory activity by modulation of $B$ cells and lymphocyte activation. Due to the effect of EOPPgfl in the second phase of the formalin test and because of the medicinal use of $P$. polygalaeflorus seed extracts for the treatment of inflammatory diseases, we hypothesized that EOPPgfl acted by a mechanism that includes an indirect anti-inflammatory effect. Thus, in order to investigate the participation of an anti-inflammatory mechanism of EOPPgfl, the effectiveness of EOPPgfl in paw edema induced by noxious stimulation was investigated. Formalin, carrageenan, and dextran were used as inflammatory agents. EOPPgfl inhibited edema from the three substances suggesting that its anti-nociceptive effect is primarily due to a large spectrum anti-inflammatory activity. It is important to highlight that this antiedematogenic activity was coherent with reports on the pharmacological effects of EOPPgfl major constituents. The sesquiterpene betaelemene, in investigations with macrophages of rats, was observed to inhibit the synthesis of PGE2 and NO (32), two potent mediators of pain and inflammation (33). An essential oil with trans-caryophyllene as a major constituent has demonstrated anti-nociceptive and antiinflammatory activity (34). Therefore, the activity of the oil can be partly explained by the fact that its main constituents present potent pharmacological effects related to the activities under study.

The investigation of the anti-inflammatory mechanism of EOPPgfl action was not the objective of this study. However, it is known that in the second phase of the formalin test, the release of inflammatory mediators occurs, and that there are differences in the edema induced by

\section{References}

1. Pinheiro MdeA, Magalhães RM, Torres DM, Cavalcante RC, Mota FS, Oliveira Coelho EM, et al. Gastroprotective effect of alpha-pinene and its correlation with antiulcerogenic activity of essential oils obtained from Hyptis species. Pharmacogn Mag 2015; 11: 123-130, doi: 10.4103/09731296.149725

2. Tisserand $R$, Balacs T. Essential oil safety: a guide for health care professionals. 1 ed. New York: Churchill Livingstone; 1995. carrageenan and dextran. Dextran, within 30 min after its injection, leads to edema mediated by histamine and 5-hydroxytryptamine (serotonin) (35), which contribute with the increase of vascular permeability and fluid extravasation (36) due to degranulation of mast cells (37). Carrageenan induces an acute vascular response with protein-rich exudate and containing large numbers of neutrophils (37). The inflammatory response has three distinct phases (22). The first relates to the release of histamine and serotonin, the second (90-150 min) is mediated by the release of bradykinin (38), and finally in the third phase, the mediator is suspected to be prostaglandin (22). In the late phase of the formalin test, the release of inflammatory mediators (20) occurs such as histamine, bradykinin, and prostaglandin (39), thus the edema must be due to such mediators.

EOPPgfl inhibited formalin-induced paw edema, and with a similar potency, inhibited the dextran-induced edema $(77.5 \%)$, and the first phase of carrageenan-induced edema (76.98\%). This suggests that EOPPgfl may be inhibiting the synthesis, release, and/or effects of histamine and serotonin.

In conclusion, EOPPgfl was active in nociception and acute inflammation in rodents at very low doses in relation to its $L D_{50}$, which is compatible with its use in folk medicine. Given the large yield of the seeds, it can be hypothesized that EOPPgfl is at least part of the active principle of the effects of the seeds preconized in folk medicine. Therefore, the current investigation provides information for the search of a novel candidate for the prevention and treatment of inflammation, either EOPPgfl (with a chemical composition here described) or a combination of its major constituents.

\section{Acknowledgments}

This research was supported by the Conselho Nacional de Pesquisa e Desenvolvimento Tecnológico (CNPq), Coordenação de Aperfeiçoamento de Pessoal de Nível Superior (CAPES), Fundação de Amparo ao Desenvolvimento Científico e Tecnológico do Estado do Ceará (FUNCAP), Financiadora de Estudos e Projetos (FINEP), and Centro Universitário Christus (UniChristus).
3. Leal-Cardoso JH, Fonteles MC. Pharmacological effects of essential of plants os the northeast of Brazil. An Acad Bras Cienc 1999; 71: 207-213.

4. Craveiro AA, Alencar JW, Matos FJA, Andrade CHS, Machado $\mathrm{MH}$. Composição química de óleos essenciais de espécie nordestina de Cróton. Ciência e Cultura 1978; 30: 326-327.

5. Barbosa AGR, Oliveira CDM, Lacerda-Neto LJ, Vidal CS, de A Saraiva R, da Costa JGM, et al. Evaluation of chemical 
composition and antiedematogenic activity of the essential oil of Hyptis martiusii Benth. Saudi J Biol Sci 2017; 24: 355361, doi: 10.1016/j.sjbs.2015.10.004

6. Coelho-de-Souza AN, Lahlou S, Barreto JE, Yum ME, Oliveira AC, Oliveira HD, et al. Essential oil of Croton zehntneri and its major constituent anethole display gastroprotective effect by increasing the surface mucous layer. Fundam Clin Pharmacol 2013; 3: 288-98, doi: 10.1111/ j.1472-8206.2011.01021.x

7. Azeredo $\mathrm{CMO}$, Santos TG, Maia BH, Soares MJ. In vitro biological evaluation of eight different essential oils against Trypanosoma cruzi, with emphasis on Cinnamomum verum essential oil. BMC Complement Altern Med 2014; 14: 309, doi: 10.1186/1472-6882-14-309

8. Orchard A, van Vuuren S. Commercial essential oils as potential antimicrobials to treat skin diseases. Evid Based Complement Alternat Med 2017; 2017: 4517971, doi: 10.1155/2017/4517971

9. Basholli-Salihu M, Schuster R, Hajdari A, Mulla D, Viernstein $\mathrm{H}$, Mustafa B. Phytochemical composition, antiinflammatory activity and cytotoxic effects of essential oils from three Pinus spp. Pharma Biol 2017; 55: 1553-1560, doi: 10.1080/ 13880209.2017.1309555

10. Anwar MA, Al Disi SS, Eid AH. Anti-hypertensive herbs and their mechanisms of action: part II. Front Pharmacol 2016; 7: 50, doi: 10.3389/fphar.2016.00050

11. Durant AA, Rodríguez C, Herrera L, Almanza A, Santana AI, Spadadora C, et al. Anti-malarial activity and HS-SPME-GCMS chemical profiling of Plinia cerrocampanensis leaf essential oil. Malar J 2014; 13: 18, doi: 10.1186/14752875-13-18

12. Lima-Accioly PM, Lavor-Porto PR, Cavalcante FS, Magalhães PJ, Lahlou S, Morais SM, et al. Essential oil of Croton nepetaefolius and its main constituent, 1,8-cineole, block excitability of rat sciatic nerve in vitro. Clin Exp Pharmacol Physiol 2006; 33: 1158-1163, doi: 10.1111/j.1440-1681. 2006.04494.x

13. Leal-Cardoso JH, Moreira MR, da Cruz GM, de Morais SM, Lahlou MS, Coelho-de-Souza AN. Effects of essential oil of Alpinia zerumbet on the compound action potential of the rat sciatic nerve. Phytomedicine 2004; 11: 549-553, doi: 10.1016/j.phymed.2003.07.008

14. Silva-Alves KS, Ferreira-da-Silva FW, Peixoto-Neves D, Viana-Cardoso KV, Moreira-Júnior L, Oquendo MB, et al. Estragole blocks neuronal excitability by direct inhibition of $\mathrm{Na}+$ channels. Braz J Med Biol 2013; 46: 1056-1063, doi: 10.1590/1414-431X20133191

15. Evangelista GL, Coelho-de-Souza AN, Santos CF, LealCardoso JH, Lopes EA, dos Santos MV, et al. Essential oil of Pterodon polygalaeflorus inhibits electromechanical coupling on rat isolated trachea. J Ethnopharmacol 2007; 12: 515-522, doi: 10.1016/j.jep.2006.08.028

16. Leonhardt $\mathrm{V}$, Leal-Cardoso $\mathrm{JH}$, Lahlou $\mathrm{S}$, Albuquerque $\mathrm{AA}$, Porto RS, Celedônio NR et al. Antispasmodic effects of essential oil of Pterodon polygalaeflorus and its main constituent $\beta$-caryophyllene on rat isolated ileum. Fundam Clin Pharmacol 2010; 24: 749-758, doi: 10.1111/j.14728206.2009.00800.x

17. Hoscheid J, Cardoso MLC. Sucupira as a potential plant for arthritis treatment and other diseases. Arthritis 2015; 2015: 379459, doi: $10.1155 / 2015 / 379459$
18. Craveiro AA, Fernandes AG, Andrade CHS, Matos FJA, Alencar JW, Machado MIL. Óleos essenciais de plantas do Nordeste. Fortaleza: UFC, 1981. 210p.

19. Koster R, Anderson M, De Beer EJ. Acetic acid for analgesic screening. Fed Proc 1959; 18: 412-417.

20. Hunskaar S, Fasmer OB, Hole K. Formalin test in mice, a useful technique for evaluating mild analgesics. Journal of Neuroscience Methods, 1985; 14: 69-76, doi: 10.1016/ 0165-0270(85)90116-5

21. Carlini ELA. Farmacologia prática sem aparelhagem. São Paulo: Savier; 1993. p 192.

22. Di Rosa M, Giroud PP, Willoughby DA. Studies on the mediators of the acute inflammatory response induced in rats in different sites by carrageenan and turpentine. J Pathol 1971; 104:15-29, doi: 10.1002/path.1711040103

23. Kubatova A, Jansen B, Vaudoisot JF, Hawthorne SB. Thermodynamic and kinetic models for the extraction of essential oil from savory and polycyclic aromatic hydrocarbons from soil with hot (subcritical) water and supercritical CO2. J Chromatog A 2002; 975: 175-188, doi: 10.1016/ S0021-9673(02)01329-8

24. Lavich TR, Cordeiro RSB, Silva PMR, Martins MA. A novel hot-plate test sensitive to hyperalgesic stimuli and nonopioid analgesics. Braz J Med Biol Res 2005; 38: 445-451, doi: 10.1590/S0100-879X2005000300016

25. Hunskaar S, Hole K. The formalin test in mice: dissociation between inflammatory and non-inflammatory pain. Pain 1987; 30: 103-114, doi: 10.1016/0304-3959(87)90088-1

26. Randolph BC, Peters MA. Analgesic effectiveness of ketorolac compared to meperidine in the rat formalin test. Anesth Prog 1997; 44: 11-16.

27. Dubuisson D, Dennis SG. The formalin test: a quantitative study of the analgesic effects of morphine, meperidine and brain stem stimulation in rats and cats. Pain 1977; 4: 16174, doi: 10.1016/0304-3959(77)90130-0

28. Shibata M, Ohkubo T, Takahashi H, Inoki R. Modified formalin test: characteristic biphasic pain response. Pain 1989; 38: 347-352, doi: 10.1016/0304-3959(89)90222-4

29. Rosland JH, Tjölsen A, Maehle B, Hole K. The formalin test in mice: effect of formalin concentration. Pain 1990; 42: 235242, doi: 10.1016/0304-3959(90)91167-H

30. Jacob JJ, Tremblay EC, Colombel M. Enhancement of nociceptive reactions by naloxone in mice and rats. Psychopharmacologia 1974; 37: 217-223, doi: 10.1007/BF004 21535

31. Velozo LS, Martino T, Vigliano MV, Pinto FA, Silva GP, Justo MdaG, et al. Pterodon polygalaeflorus essential oil modulates acute inflammation and $\mathrm{B}$ and $\mathrm{T}$ lymphocyte activation. Am J Chin Med 2013; 41: 545-563, doi: 10.1142/S019 $2415 \times 13500390$

32. Lim SS, Shin KH, Ban HS, Kim YP, Jung SH, Kim YJ, et al. Effect of the essential oil from the flowers of Magnolia sieboldii on the lipopolysaccharidre-induced of nitric oxide and prostaglandin E2 by rat peritoneal macrophages. Planta Med 2002; 68: 459-462, doi: 10.1055/s-2002-32085

33. Contran RS, Kumar V, Robbins SL. Robbins Patologia estrutural e funcional. 5 ed. Rio de Janeiro: Guanabara Koogan; 1996.

34. Sousa OV, Silvério MS, Del-Vechio-Vieira G, Matheus FC, Yamamoto $\mathrm{CH}$, Alves MS. Antinociceptive and antiinflammatory effects of the essential oil from Eremanthus 
erythropappus leaves. J Pharm Pharmacol 2008; 60: 771777, doi: 10.1211/jpp.60.6.0013

35. Katz LB, Theobald HD, Bookstaff RC, Peterson RE. Charecterization of the enhancced paw edema response to carrageenan and dextran in 2,3,7,8-tetrachorodibenzo-pdioxin-treated rats. J Pharmacol Exp 1984; 230: 670-677.

36. Parrat JR, West GB. Inhibition by various substances of edema formation in the hind paw of the rat induced by 5-hydroxytryptamine, histamine, dextran, egg white and compound 48/80. Brit J Pharm Chemot 1957; 13: 65-70, doi: 10.1111/j.1476-5381.1958.tb00192.x
37. Lo TN, Almeida AP, Beavan MA. Dextran and carrageenan evoke different inflammatory response in rat with respect to composition of infiltrates and effect of indometacin. J Pharmacol Exp Ther 1982; 221: 261-267.

38. Burch RM, DeHaas C. A bradykinin antagonist inhibits carrageenan edema in rats. Naunyn Schmiedebergs Arch Pharmacol 1990; 342: 189-193, doi: 10.1007/BF00166963

39. Corrêa CR, Calixto JB. Evidence for participation of B1 and B2 kinin receptors in formalin-induced nociceptive response in the mouse. Br J Pharmacol 1993; 110: 193-198, doi: 10.1111/j.1476-5381.1993.tb13791.x 